\title{
PENERAPAN BUDAYA PAMALI DAN ADAT ISTIADAT DALAM KEHIDUPAN MASYARAKAT KAMPUNG ADAT KUTA KABUPATEN CIAMIS JAWA BARAT
}

\author{
Oleh: \\ SRI DWI FAJARINI, DHANURSETO \\ Prodi Ilmu Komunikasi FISIP Universitas Muhammadiyah Bengkulu \\ Prodi Ilmu Komunikasi FISIP Universitas Bengkulu
}

\begin{abstract}
Indonesia has nations and culture scattered around 17,000 ranges island, starting from sabang to the west, to marauke to the east irian jaya.Life the people in indonesia has the pattern formed based on the influence of local culture place they live.This means culture and style community life in indonesia varies.One of the influential in the life of people will examined is a culture and the community mores their kuta, kabupaten ciamis, west java. Their customary kuta shows a pattern spread out and did not feel certain. This research aims to review the application of local cultural factors in the life of the indigenous people of kampung kuta. The methodology that was used is mixed methods, with a design research used in this research was sequential exploratory designs. The data collection was done by interviews, observation and spreading kampung kuta watchful such research to the community. Results or research is the their kuta always apply cultural factors and customstheir kuta in her life, starting with the smallest to great things though because people would hold fast in culture pamali.
\end{abstract}

Keyword : culture, kuta village, the life of the people

\section{PENDAHULUAN}

Indonesia terdiri atas berbagai suku bangsa dan kebudayaan yang hidup tersebar di sekitar 17.000 gugusan pulau, mulai dari Sabang di sebelah Barat, sampai ke Marauke di sebelah Timur Irian Jaya. Berbagai suku bangsa tersebut terdapat beragam kebudayaaan dan adat istiadat. Budaya adalah keyakinan dan perilaku yang di aturkan atau di ajarkan manusia kepada generasi berikutnya (Taylor, 1989) sedangkan menurut Sir Eduarel Baylor (1871) dalam Andrew dan Boyle (1995), budaya adalah sesuatu yang kompleks yang mengandung pengetahuan, kepercaayaan seni, moral hukum, kebiasaan, dan kecakapan lain yang merupakan kebiasaan manusia sebagai anggota komunikasi setempat. Dewasa ini, kebudayan dan adat istiadat masingmasing daerah memiliki ciri khas masingmasing yang tidak dapat dikatakan lebih baik dari kebudayaan dan istiadat lainnya. Nilai-nilai budaya dan adat istiadat dapat bertahan dengan baik jika tetap adanya komunikasi dan peran serta segala pihak untuk mempertahankan budaya dan adat istiadat tersebut.

Menurut J. J Honigmann (dalam Koenjtaraningrat, 2000) kebudayaan terdiri dari tiga gejala yaitu : (1) ideas, (2) activities, dan (3) artifact, dan ini diperjelas oleh Koenjtaraningrat yang mengistilahkannya dengan tiga wujud kebudayaan :

a. Wujud kebudayaan sebagai suatu yang kompleks dari ide-ide, gagasan- 
gagasan, nilai-nilai, norma-norma, peraturan dan sebagainya.

b. Wujud kebudayaan sebagai suatu kompleks aktivitas serta tindakan berpola dari manusia dalam masyarakat

c. Wujud kebudayaan sebagai bendabenda hasil karya manusia.

Kebudayaan akan menimbulkan atau melahirkan suatu sistem nilai budaya, pandangan hidup, dan ideologi. Sistem nilai budaya adalah tingkat dan paling abstrak dari adat istiadat. Sebabnya ialah karena nilai budaya terdiri dari konsep konsep mengenal segala sesuatu yang dinilai berharga dan penting oleh warga suatu masyarakat, sehingga dapat berfungsi sebagai suatu pedoman orientasi pada kehidupan para warga masyarakat yang bersangkutan (Koenjajaraningrat, $2011: 76)$

Kondisi inilah yang mengharuskan masyarakat mampu untuk tetap terus mempertahankan dan menjalankan nilainilai budaya dan adat istiadat tersebut. Sehingga peninggalan dari nenek moyang yang sudah sejak dahulu ada masih dapat dipertahankan keberadaannya. Dewasa ini seturut perkembangan dan dinamika kehidupan yang semakin global, muncul pertanyaan: Bagaimana budaya, tradisi dan adat dapat terus dipertahankan?, Bagaimana dengan Kampung Kuta, Kabupaten Ciamis?, Apakah budaya, tradisi dan adat dapat terus dipertahankan, dilestarikan dan turunkan ke generasi muda? dan Bagaimana dengan budaya, tradisi dan adat di Kampung Kuta sekarang ini?.

Kampung Kuta terletak di Desa Karangpaningal, Kecamatan Tambaksari, berbatasan dengan Jawa Tengah dan dikenal sebagai Kampung adat. Kampung Adat Kuta berdiri pada masa Kerajaan Galuh. Kampung adat ini dihuni oleh masyarakat yang dipimpin oleh kepala adat dan kepala keluarga yang memegang teguh kearifan lokal budaya pamali (tabu), tradisi, agama, serta norma-norma yang diberlakukan dan harus dipatuhi untuk menjaga keseimbangan alam dan keselarasan harmoni tatanan hidup sosial masyarakat. Budaya Pamali (tabu) adalah suatu aturan atau norma yang mengikat kehidupan mayarakat adat itu sendiri mulai dari bagun hingga tidur kembali. Aturan atau norma tersebut sudah menjadi budaya dalam kehidupan masyarakat Desa Adat Kampung Kuta, Kabupaten Ciamis, Jawa Barat. Selain Budaya Pamali, masyarakat Kampung Kuta memiliki adat istiadat yang terus dilestarikan dan dijaga agar tidak dilupakan oleh generasinya salah satunya ialah Upacara Adat Kampung Kuta. Penelitian yang dilakukan oleh penulis hendak mendeskripsikan tentang penerapan budaya pamali dan adat istiadat dalam kehidupan masyarakat Kampung Kuta, Ciamis, Jawa Barat. Penulis dalam penelitiannya hendak memperlihatkan akan penerapan budaya pamali dan adat istiadat Kampung Kuta, Ciamis, Jawa Barat. Apakah budaya dan adat istiadat berperan dalam kehidupan masyarakat kampung kuta? Bagaimana penerapan budayapamali dan adat istiadat dalam kehidupan masyakat Kampung Kuta?.

\section{METODE PENELITIAN}

Metode yang digunakan dalam penelitian ini adalah mixed methods. Penelitian ini merupakan langkah peneliti dengan menggabungkan dua bentuk penelitian yang telah ada sebelumnya yaitu penelitian kualitatif dan kuantitatif. Menurut Craswell (2010:5), penelitian campuran merupakan pendekatan penelitian yang mengkombinasikan antara penelitian kualitatif dengan penelitian kuantitatif. Menurut pendapat Sugiyono (2011:404), menyatakan bahwa metode penelitian yang mengkombinasikan atau menggabungkan antara metode kuantitatif dan kualitatif untuk digunakan secara bersama-sama dalam suatu kegiatan penelitian sehingga diperoleh data yang komprehensif, valid, reliable, dan objektif.

Desain penelitian yang digunakan dalam penelitian ini adalah sequential exploratory designs, yaitu mengumpulkan dan menganalisis data kualitatif kemudian 
mengumpulkan dan menganalisis data kuantitatif. Pada penelitian ini, data kuantitatif digunakan untuk menjelaskan data kualitatif. Data kualitatif didapat melalui wawancara dengan partisipan secara mendalam. Metode kualitatif digunakan untuk memperoleh gambaran mengenai budaya dan adat istiadat lokasi dan tempat penelitian. Dengan lokasi penelitian dilaksanakan di Kampung Kuta, Desa Karang Paningal, Kecamatan Tembak Sari, Kabupaten Ciamis, Jawa Barat. Populasi penelitian adalah masyarakat adat, pihak-pihak pengurus dan pimpinan adat.

Pada penelitian ini dilakukan teknik pengambilan sampel dengan menggunakan simple random sampling. Variabel bebas dalam penelitian ini adalah Penerapan budaya dan adat istiadat kampung kuta. Sedangkan variabel terikat dalam penelitian ini adalah kehidupan masyarakat Kampung Kuta. Instrumen penelitian yang digunakan adalah lembar observasi, angket, wawancara penerapan budaya dan adat istiadat Kampung Kuta. Analisis data dilakukan secara analisis kuantitatif dan kualitatif. Menurut miles dan hubermas, data kualitatif diperoleh dari reduction, data display dan conclusion drawing/verification (Sugiyono,2011:334), dan analisis data kuantitatif untuk mengetahui korelasi penerapan budaya dan adat istiadat dalam kehidupan masyarakat Kampung Kuta dilakukan uji kolerasi dan uji regresi.

\section{HASIL DAN PEMBAHASAN}

Masyarakat Kampung Kuta merupakan suatu komunitas yang memiliki kesamaan suku, agama dan ras. Hal ini disebabkan karena mereka merupakan suatu kesatuan, yang memiliki ikatan yang kuat satu sama lain karena merupakan satu keturunan dari leluhur yang sama. Masyarakat Kampung Kuta memiliki kearifan lokal yang sudah diwariskan oleh leluhur. Kearifan lokal masih tetap dijalankan masyarakat Kuta tersebut adalah adat dan budaya pamali. Pamali (tabu) adalah suatu aturan atau norma yang mengikat kehidupan mayarakat adat. Adapun karakteristik dari pamali itu sendiri adalah sebagai berikut :

1. Pamali dalam perkembangannya menjadi suatu aturan yang sudah melekat pada budaya lokal yang ada dan berkembang pada masyarakat Kampung Kuta.

2. Pamali dengan segala aturan-aturan khusus yang mempengaruhi perilaku masyarakat Kampung Kuta dan bersifat jangka panjang.

3. Pamali memandang bahwa alam dan budaya merupakan satu kesatuan yang memiliki hubungan timbal balik.

4. Terdapat komitmen yang mampu memandang bahwa lingkungan lokal bersifat unik dan merupakan tempat yang tidak dapat berpindah-pindah.

Hal ini dibenarkan oleh Bapak Warsim selaku Ketua Adat Kampung Kuta :

"Budaya dan adat pamali di kampung kuta itu sudah sama hal nya seperti nasi yang selalu di butuhkan dan diinginkan orang. Disaat orang memakan nasi, disaat itulah mereka merasakan kebahagiaan, senang, dan mampu menjadi perantara kebersamaan, begitu juga dengan budaya dan adat; disaat mereka menjalankannya maka mereka akan merasakan kebahagiaan, senang, hidup lebih terarah, serta budaya dan adat dapat menjadi perantara silaturahmi atau pengerat silaturahmi sesama" (wawancara dengan Warsim)

Tabu atau pamali terungkap dalam prinsip-prinsip utama yang dikemukan ketua adat ataupun kuncen sebagai aturanaturan adat yang harus dipatuhi dan diyakini kebenarannya. Hal tersebut dibenarkan oleh Aki Maryono selaku kuncen Kampung Adat Kuta, beliau menyampaikan bahwa:

"Pamali itu merupakan aturan-aturan adat yang mengatur segala hal tentang kehidupan masyarakat mulai dari sumber daya alam yang dimiliki untuk dirawat dan dimanfaatkan 
dengan baik, dan aturan tentang kehidupan sehari-hari mulai dari bagun tidur, MCK, kerja, dan lain sebagainya. Semua itu sudah diatur, jadi dengan adanya aturan ini masyarakat harus menjalankannya. Jika dilanggar masyarakat akan mendapatkan hukuman dan teguran dari karuhun"

Prinsip-prinsip utama dalam adat dan budaya pamali dianggap sebagai kearifan tradisional/lokal karena berasal dari warisan leluhur yang telah berlaku secara turun temurun. Di kampung kuta, prinsip tradisional tersebut masih berlaku sebagai pranata sosial yang dapat mengendalikan perilaku manusia dalam berinteraksi dengan alam atau dengan sesamanya. Prinsip-prinsip utama diatas dibedakan menjadi dua bagian yaitu prinsip-prinsip utama yang berhubungan dengan pengelolaan sumberdaya alam dan prinsip yang berhubungan dengan kehidupan sehari-hari. Untuk prinsip utama dalam pengelolaan sumber daya alam merupakan prinsip yang paling utama dan paling ditekankan oleh masyarakat kampung kuta, yaitu sebagai berikut:

1. Teu kenging disapatu atawa sidandal, teu kenging make emas lamun rek asup ka tempat keramat

(Tidak boleh menggunakan sepatu atau sendal, tidak boleh menggunakan perhiasan dari emas jika memasuki tempat-tempat keramat)

Tabu ini mengandung nilai bahwa masyarakat kampung kuta sangat menghormati sikap-sikap yang sederhana, bersahaja, kebersamaan dan patuh kepada norma-norma sosial yang berlaku. Mereka memiliki sifat religius yang sangat tinggi serta menghormati peninggalan leluhur, yaitu tempat keramat. Tempat keramat yang dimaksud adalah sebuah kawasan hutan yang dihuni oleh makhlukmakhluk gaib yang menguasai dan menjaga kampung kuta. Dimana setiap orang yang akan masuk ke kawasan hutan keramat tidak boleh meggunakan sepatu, sandal, dan perhiasan.

2. Teu kenging nyiduh, kahampangan, kabeuratan di tempat keramat

(Tidak boleh meludah, membuang air kecil, buang air besar di tempat keramat)

Tabu tersebut merupakan satu bentuk dalam menjunjung tinggi nilai-nilai kebersiahan dan kesopanan. Pemeliharaan hubungan alam dengan manusia yang selaras dan seimbang tercermin dalam ungkapan tersebut. Jika seseorang meludah, membuang air kecil bahkan air besar maka akan menyebabkan lingkungan alam akan tercemar.

3. Jalma nu maot teu kenging dipendem di kuta

(Setiap orang yang meninggal tidak boleh dikuburkan di Kampung Kuta)

Tabu ini mencerminkan kepercayaan masyarakat Kampung Kuta terhadap mitos leluhur dan penghargaan terhadap leluhurnya. Salah satu karuhun masyarakat yaitu $\mathrm{Ki}$ Bumi yang dimakamkan di Marga, maka setiap yang meninggal akan dikuburkan di Cibodas.

4. Teu kenging ngadamel bumi ku tembok, suhunan teu kenging $k u$ kenteng, tapi kedah ku kiray atanapi injuk

(Tidak boleh membuat rumah dari bahan tembok, atap tidak boleh menggunakan genting, tetapi harus menggunakan alang-alang atau ijuk)

Tabu ini menunjukkan satu simbol jika bahan-bahan yang berasal dari tanah (tembok dan genting) serta tempatnya melebihi batas kepala manusia, sama artinya manusia berasa dalam tanah atau dikubur. Artinya sama dengan orang mati, padahal di dunia ini manusia hidup tidak boleh seperti orang mati yang tidak berdaya. Tujuan lain dari tabu ini adalah berhubungan juga dengan kondisi tanah kampung kuta yang labil. 
5. Teu kenging ngadamel sumur jero (Tidak boleh membuat sumur dalam)

Tabu ini berupa anjuran sekaligus larangan yang harus diterapkan oleh masyarakat Kampung Kuta ketika akan membuat sumur di rumah mereka. Sumur yang dibuat tidak boleh terlalu dalam.

Kelima norma tersebut merupakan norma adat yang sangat mengikat masyarakat karena sudah dilakukan secara turun menurun dan diketahui oleh seluruh masyarakat. Jadi yang ditekankan dalam adat dan budaya pamali adalah pelestarian bentuk rumah, larangan menguburkan mayat di Kampung Kuta, larangan membuat sumur, dan peraturan mengenai hutan keramat. Kelima hal itu masih dipegang teguh oleh seluruh masyarakat Kampung Kuta sehingga tidak ada yang berani melanggarnya. Kelima hal tersebut yang menjadi fokus dari adat dan budaya pamali yang ada di kehidupan masyarakat kampung kuta. Adat pamali memiliki aturan-aturan yang harus ditaati oleh masyarakat Kampung Kuta itu sendiri. Dimana setiap orang yang melanggar selalu mendapatkan balasan yang diyakini berasal dari karuhun mereka yang murka. Apabila ada seseorang yang melanggar, para sesepuh kampung, kuncen, dan ketua adat akan musyawarah atau diskusi untuk mengingatkan pelanggar untuk merubah perilakunya.

Budaya pamali dianggap sebagai kearifan tradisional/lokal karena berasal dari warisan leluhur yang telah berlaku secara turun temurun. Budaya pamali merupakan suatu aturan adat yang kemudian aturan tersebut sudah menjadi budaya di masyarakat. Prinsip-prinsip yang terkandung dalam budaya pamali mampu mengatur kehidupan masyarakat Kampung Kuta, Kabupaten Ciamis. Salah satunya dalam segi pembangunan di desa tersebut. Dimana masyarakat membangun rumah, masjid dan tempat pertemuan di Kampung Kuta sesuai dengan aturan dan normal yang terkandung dalam budaya pamali yakni Teu Kenging Ngadamel Bumi
Ku Tembok, Suhunan Teu Kenging Ku Kenteng, Tapi Kedah Ku Kiray Atanapi Injuk, artinya: Tidak boleh membuat rumah dari bahan tembok, atap tidak boleh menggunakan genting, tetapi harus menggunakan alang-alang atau ijuk. Karena masyarakat menyakini bahwa jika mereka membangun rumah tidak sesuai dengan aturan yang ada mereka akan mendapatkan teguran dari karuhun. Dimana dahulu pernah ada masyarakat ingin membangun rumah dengan bahan beton, namun dikarenakan itu melanggar aturan dan norma dari kampung adat Kuta sehingga masyarakat Kampung Kuta yang membangun rumah tersebut ditegur oleh karuhun. Hal tersebut diceritakan kembali oleh pak Warsim dalam wawancara 19 Agustus 2017:

"Dahulu ada masyarakat Kampung Kuta yang mencoba untuk membuat rumah dengan menggunakan bahanbahan yang tidak sesuai aturan adat Kampung Kuta yakni menggunakan beton. Saat sudah diingatkan, namun orang tersebut tetap saja membuat rumah tersebut. Hingga saat orang tersebut di tegur oleh karuhun, orang tersebut tertimpa sakit. Hingga rumah tersebut dihancurkan untuk dibuat sesuai aturannya"

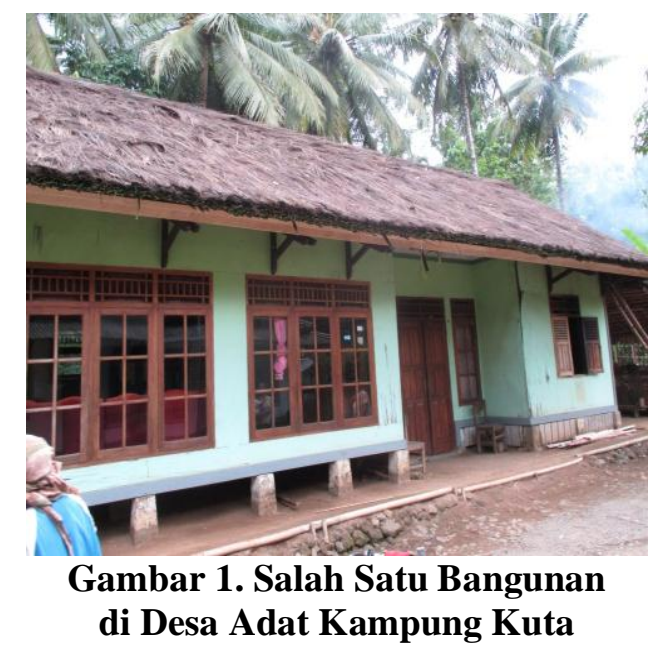

Berdasarkan data yang terkumpul dari perwakilan masyarakat yang berjumlah 15 orang responden didapatkan hasil bahwa penerapan kebudayaan dan 
adat istiadat dalam kehidupan masyarakat Kampung Kuta sebagian besar sudah menerapkan kebudayaan dan adat istiadat dalam kehidupannya dengan persentase $86,6 \%$.

Table 1

Penerapan Budaya Pamali dan Adat Istiadat

\begin{tabular}{|c|l|c|c|}
\hline No & \multicolumn{1}{|c|}{ Jawaban } & Jumlah & Persentase \\
\hline 1 & Menerapkan & 13 & $86,6 \%$ \\
\hline 2 & $\begin{array}{l}\text { Tidak } \\
\text { Menerapkan }\end{array}$ & 0 & $0 \%$ \\
\hline 3 & Netral & 2 & $13,4 \%$ \\
\hline \multicolumn{2}{r|}{ Total } & 15 & $100 \%$ \\
\hline
\end{tabular}

Sumber : Data Peneliti Tahun 2017

Berdasarkan tabel diatas menunjukkan bahwa responden yang menyatakan menerapkan budaya dan adat istiadat sebanyak $86,6 \%$ dan sebanyak $13,4 \%$ menyatakan netral. Responden yang menjawab menerapkan budaya pamali dalam kehidupan sehari-hari dimana semua prinsip-prinsip yang terkandung dalam budaya pamali dijalankan dengan baik serta adat istiadat Kampung Kuta tetap terus dijalankan dan dilestarikan. Sedangkan responden yang menjawab netral, responden tersebut bukan tidak menjalankan, melainkan responden tesebut menjalankan namun terdapat beberapa prinsip yang belum dijalankan semua. Responden menerapkan budaya dan adatistiadatKampung Kuta dalam kehidupan sehari-hari sebagai sebuah prinsip dan aturan baku yang mengatur dan menata apa yang diperbolehkan dan apa yang tidak di perbolehkan. Selain itu terdapat salah satu adat istiadat Kampung Adat Kuta yang tidak dapat ditinggalkan penerapannya yakni mengenai upacara adat yang ada di Kampung Kuta. Upacara adat ini terdiri dari:

1. Upacara Nyuguh: Ritual ini dilaksanakan pada bulan Maulid, dan ditunjukan untuk memberi sesaji kepada arwah para leluhur dan penguasa Leuweung Gede, serta ungkapan rasa syukur kepada Illahi

2. Hajat Bumi: Ritual ini biasanya dilaksanakan antara bulan September sampai November dimana pada bulan bulan ini musim penghujan tiba, ini merupakan pertanda musim tanam raya bisa dimulai

3. Babarit: Ritual ini dilakukan oleh seluruh warga dusun Kuta secara bersama - sama setelah terjadinya bencana alam berupa Lini (gempa bumi), kemarau panjang atau phenomena alam lainnya

4. Saman: Ritual ini dilakukan oleh seluruh warga dusun Kuta secara bersama - sama sehari menjelang bulan Puasa (Munggahan), upacara yang berlangsung di pemakaman umum dusun Cibodas. Ikrar oleh kuncen dilanjutkan dengan membersihkan seluruh makam secara masal dan diakhiri dengan makan bersama.

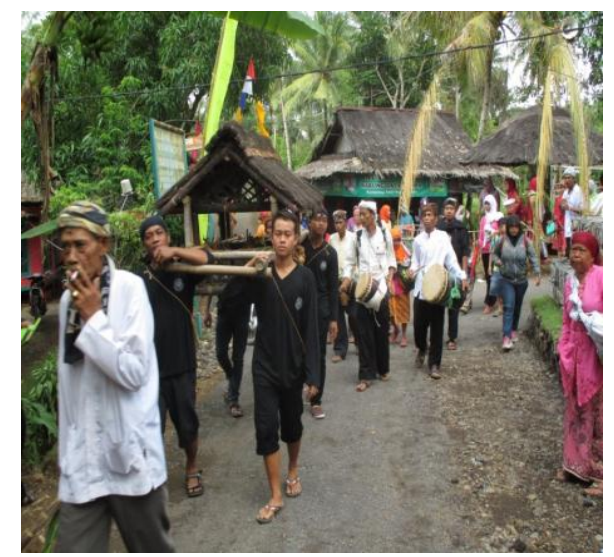

Gambar 2. Upacara Nguyuh

Upacara-upacara adat di Kampung Kuta ini merupakan kegiatan rutin yang dilakukan oleh masyarakat adat Kampung Kuta dalam menerapkan budaya dan adat istiadat yang mereka jalani dan mereka yakini. Masyarakat Kampung Adat Kuta merupakan masyarakat yang masih memegang teguh budaya dan adat istiadat yang nenek moyang atau karuhun dimana masyarakat meyakini dengan budaya terutama budaya pamali dan adat istiadat yang mereka jalani mampu menjaga keseimbangan alam dan keselarasan 
harmoni tatanan hidup sosial masyarakat Kampung Adat Kuta, Kabupaten Ciamis, Jawa Barat.

\section{PENUTUP}

\section{Kesimpulan}

Dari penelitian yang dilakukan oleh peneliti dan berdasarkan analisis hasil penelitian beserta pembahasannya, dapat disimpulkan bahwa masyarakat Kampung Kuta sebagai suatu pranata sosial yang dimana masyarakat Kampung Kuta sebagai suatu komunitas yang memiliki kesamaan suku, agama dan ras. Dimana mereka merupakan suatu kesatuan, yang memiliki ikatan yang kuat satu sama lain karena merupakan satu keturunan dari leluhur yang sama.

Masyarakat Kampung Kuta sebagai masyarakat adat yang memegang teguh ada dalam setiap lini kehidupannya, tetap menjalankan dan menerapkan warisanwarisan yang telah ditinggalkan oleh nenek moyang dan leluhurnya. Pada budaya pamali, masyarakat Kampung Kuta selaku masyarakat adat tetap menjalankan budaya pamali dalam kehidupannya. Karena di dalam budaya pamali sudah diatur prinsip-prinsip yang mengatur tentang kehidupan masyarakat Kampung Kuta. Dari penelitian yang dilakukan didapatkan hasil bahwa 86,6\% masyarakat menerapkan budaya pamali dalam kehidupan sehari-hari masyarakat
Kampung Kuta. Dimana jumlah tersebut tidak kecil, jumlah tersebut sudah cukup mendominasi hasil, bahwa masyarakat Kampung Kuta selalu menerapkan budaya pamali dan adat istiadat Kampung Kuta dalam kehidupan sehari-hari.

\section{DAFTAR PUSTAKA}

Aryono, Suyono. 1985. Kamus Antropologi. Jakarta, Akademika Pressindo.

Creswell, John W. 2010. Research Design Pendekatan Kualitatif, Kuantitatif, dan Mixed. Yogyakarta, Pustaka Pelajar.

Koentjaraningrat. 2000. Pengantar Ilmu Antropologi. Jakarta, Rineka Cipta

Kusmayadi, Edi, Satori, A, Nurohman, Yuliawati, Widiastuti, Andrias, Ali. 2009. Kajian Sosial, Budaya dan Politik Masyarakat Adat Kampung Kuta. Tasikmalaya: LPPM Unsil

Leininger, M. 1991. Culture Care Diversity And Universality: A Theory Of Nursing. New York, National League For Nursing Press.

Sugiyono. 2011. Metode Penelitian Pendidikan. Bandung, Alfabeta

Sugiyono. 2014. Metode Penelitian Kuantitatif Kualitatif dan $R \& D$. Bandung, Alfabeta

Sukmadinata Nana Syaodih. 2007. Metode Penelitian Pendidikan. Bandung, Remaja Rosda Karya. 